\title{
How teachers' individual autonomy may hinder students' academic progress and attainment: professionalism in practice
}

\author{
Author - Christopher Day \\ Affiliation - University of Nottingham \\ Contact - Christopher.day@ nottingham.ac.uk
}

\begin{abstract}
This paper reports a three-year case study of a primary school in England, in which a recently appointed principal attempted to build 'collegial professional autonomy' (Frostenson, 2015) within a push to improve students' progress and attainment. The research examined the tensions between staff who embraced the principal's agenda for collegially agreed change, and whose students' academic progress and performance improved over a three-year consecutive period when measured in terms of students' entry-level attainment and socioeconomic factors, and staff who asserted their right to 'individual professional autonomy' and whose students' academic progress and attainment declined. The research findings: i) challenge claims that reform necessarily results in school cultures of compliancy, de-professionalisation, and the technicisation of teaching; ii) raise issues concerning the pedagogical leadership of principals in a devolved, ' self-governing' school system; and iii) question teachers' entitlements to individual professional autonomy where this is associated with students' continuing academic under performance.
\end{abstract}

Key words: autonomy; professionalism; principal pedagogical leadership; student progress and achievement

\section{Introduction}

'For the staff, the main challenge is making sure that your children are making the progress that they need to be making, to make sure that you are making the best for the children' (T1)

Schools in many countries across the world have been subject to a raft of government-initiated reforms over the past three decades. These are claimed by policy makers to be a means of building the human, economic, and social capital of citizens who live and work in increasingly competitive and turbulent global environments. In many countries the reforms emphasize devolved governance, diversification of teacher qualification routes, setting, monitoring and assessing regional and national standards of teaching. Among the consequences for 
schools and teachers have been increased workloads, intensification of the teaching task; and more transparent contractual accountabilities through public, results-driven assessment. It is claimed that such reforms have led to 'the erosion of responsible, accountable and democratic professionalism' (Biesta, 2015:82), as neoliberal policies have burdened individuals 'with tasks that used to be the responsibilities of governments and the state' (ibid,:76). One important negative effect of reforms is that the professional space for teachers to exercise individual professional autonomy in their classrooms about students' academic progress and attainment has become more limited.

The aims of the study were to i) examine, among staff in one primary school in England, the continuing claims that reform necessarily results in school cultures of compliancy, de-professionalisation, and the technicisation of teaching; ii) discuss the implementation and effects over a three year consecutive period of the pedagogical leadership of a newly appointed principal in a devolved, 'selfgoverning' school system, as he attempted, through promoting 'collegial professional autonomy' (Frostenson, 2015), to persuade teachers to be more rigorous in their use of data-informed teaching and learning in classrooms. The research iii) raises issues concerning teachers' entitlements to classroom autonomy where this is associated with students' continuing academic under performance.

\section{Methodology}

Constructivist theory underpinned the research conceptualisation, design, conduct and interpretation. This assumes that people form meanings from their actions in relation to space, time and circumstance (Charmaz, 2014). A case study research design (Wellington, 2000; Yin, 2009) was considered to be the most appropriate means to enable the construction of detailed, multi-perspective, rich accounts of the impact of the principal on staff, as they responded to his promotion of 'collegial autonomy', and the perceived and measured associations between this and students' academic progress and attainment over a three-year period. Data were collected from all teachers $(\mathrm{N}=14)$, principal, school administrator, secretary, chair of governors, and two focus groups of parents and students at one primary school by means of semi-structured interviews in each of three consecutive years. In addition, documentation about the school's staffing history, external judgements of the school's standards by Ofsted (Office of Standards in Education), and student attainment history in national tests were collected over that period. The principal was interviewed on three occasions in Year 1 and once in Year 2 and 3. Each interview took around 45 minutes. Teachers and administrative staff members were interviewed once in each of these years for around 30 minutes each. All data were digitally recorded, transcribed, and categorized into emerging themes by using analytical matrices and thematic analysis (Miles \& Huberman, 1984). Datasets were re-interrogated and triangulated in order to identify patterns and relations between the different themes and the participants. The researcher had no previous relationship with the school, and the research was unfunded.Ethical agreements were established with all participants so that consent, the right to withdraw, non-attribution and anonymity were guaranteed. 


\section{Professionalism and autonomy in a neo-liberal reform context}

Over the last four decades in England, USA, Australia and many other jurisdictions, the teaching profession has generally become more subordinate to i) market forces (e.g. parental choice, transparency and feedback); ii) increased competition and public forms of contractual accountability; and iii) more managerial control through increases in external bureaucratic regulations, the development of national teaching standards and external school inspection. Performance management cultures are now, 'embedded in policies and practices of education, and are especially evident around government interventions to impose professional standards on the teaching profession' (Sachs and Mockler, 2012:33) Ball and others have described the system in terms of 'performativity' and associate this with oppressive, 'neo-liberal' environments that stifle teacher agency:

Performativity is enacted through measures and targets against which we are expected to position ourselves but often in ways that also produce uncertainties about how we should organize ourselves within our work...Performativity 'works' most powerfully when it is inside our heads and our souls. That is, when we do it to ourselves, when we take responsibility for working harder, faster and better, thus 'improving' our 'output', as part of our sense of personal worth and the worth of others... Performativity is a key mechanism of neo-liberal management, a form of hands-off management that uses comparisons and judgements in place of interventions and direction...

(Ball, 2012:31-32)

In English schools, standard setting processes for teachers' work within classrooms now often mimic those set externally as a means of judging their performance, and have become the norm in schools in England (Hall and Noyes, 2009) and many other countries.

Taken together, these reforms are claimed to have reduced (though not eliminated) teachers' capacity to exercise of autonomy (Apple, 2008, Ball, 2012, Ozga, 2008; Troman, 2008). Historically, individual autonomy has been regarded as a central pillar of teachers' professionalism, and is related closely to the expectation that they have the right to exercise discretion in decision-making in the classroom (Lortie,1975;Goodlad, 1990;Hargreaves \& Fullan, 2012), Much of the academic literature assumes that teachers will exercise discretion within an overall ethic of moral or ethical responsibility for adding value in a range of ways, through what they do and how they do it, to their students' progress and achievement. On this basis, texts continue to present 'autonomy' as an essential component of teachers' professionalism, asserting that, 'The quality of public education is undermined when teachers are held accountable to an external authority, rather than to themselves, their colleagues, and their professional associations' (HyslopMargison and Sears, 2010:1), and that neoliberal reforms have, 'eroded their autonomy of judgment and conditions of work' (Hargreaves, 2003:11).

It would be difficult to argue against the claim that, to make wise decisions, 'teachers must be aware of the ways in which students learning can unfold in the context of 
development, learning differences, language and cultural differences, and individual temperaments, interests, and approaches to learning' (Bransford, Darling-Hammond \& Lepage, 2005:1). However, although autonomy itself is often used as a broad, generalized term, in practice it is a, 'vexed concept.... grounded within a complex relation to the influence and authority of individuals, ideas, and ideals we [teachers] reject or claim as our [their] own' (Pitt, 2010:1). In that sense, it may be understood not as being static or stable, but rather as containing competing elements of constraint, freedom, responsibility and accountability that may vary from teacher to teacher, school to school, and jurisdiction to jurisdiction.

\section{A Different Kind of Autonomy in Practice?}

There are a number of writers and researchers who, whilst acknowledging the views of 'critical theorists' (e.g. Ozga, 2012; Ball, 2012) that the contexts for teachers' exercise of autonomy have changed under successive reforms, do not accept that these have necessarily led to their de-professionalization. As a result of close examination of teachers and their workplaces, they propose a more nuanced, evidence-based view in which it is possible for schools and their teachers to be active agents, able to mediate reform, maintain an ethic and practice of care, commitment and a measure of autonomy, albeit reduced (Hargreaves, 2007, Day, 2017, Hargreaves, 2018).

One means of re-examining and re-defining autonomy in practice has been developed by a Norwegian researcher, who questioned the validity of the work of those who hold to a general view of its meaning in and impact on classroom practice.

'Could it be that the literature on the de-professionalism of the teaching profession jumps to a questionable conclusion? Is it too quick to assume that the general loss of professional autonomy implies that professionals actually lose their autonomy at the level of practice?' (Frostenson, 2015, p. 20).

In doing so, he took account of the variations that are likely to occur in devolved systems of school governance, developing a three-level typology:

i) 'General professional autonomy' which refers to changes in the frames' within which teachers work (governance, school systems, reforms through which government influence through determining curriculum 'legitimate', pedagogies, and assessment measures.

ii) 'Collegial professional autonomy'- decentralisation has increased school autonomy, as against teacher autonomy, as in the case of England's move to embrace 'systems' management through the establishment of multi-academy trusts, chains, teaching school allowances and other forms of collegial arrangements in which individual managers (Chief Executive Officers or Executive Headteachers) have the authority to influence teachers' ways of working. In practice, most of these systems operate through the exercise of collegial forms of autonomy: 
'...from a practice perspective ........ the corollary of such requirements may be increased autonomy in collegial form' (Frostenson, 2015 p. 24)

iii) 'Individual professional autonomy' - In the third stand, a 'substantial sphere of action and decision-making.... [is].... tied to the professional practice of the individual teacher' (Frostenson, 2015: 24). He identifies a key tension in the practice of individual autonomy as being, 'in the use of metrics, or other forms of evaluation as decisive criteria for quality in which the teacher becomes accountable, rather than responsible, implying that the teacher loses the traditionally enjoyed mandate of trust' (ibid, p.25). In short, 'what it means to be a teacher in one school might be something quite different in another' (ibid, p .26).

This research used Frostenson's typology as a frame for understanding how autonomy was promoted and practiced in one primary school. It found differences between teachers that led to tensions, and were associated with the 'value-added' progress and attainment of students.

\section{The school context}

River Edge Primary (4-11year old students) school was located in an affluent suburb of a medium sized city. The majority of its 293 students were drawn from white British middle-class families that lived near the school. There was a small but growing proportion of students from other, less socio economically advantaged, areas. It had well below the national average of students eligible for free school meals, a proxy for socio-economic disadvantage, $(8.9 \%$ v $26.8 \%)$, and below average students with learning and behavioural difficulties and special educational needs. There were 10 full-time teachers, many of whom had been teaching at the school for more than 20 years, and 4 teachers working part--time, as part of a job share scheme. In addition, there were 11 qualified and 1 unqualified classroom Teaching Assistants (who support teachers in classrooms in English schools).

Recently, the school had become a part of a 'multi-academy trust' (MAT), one of many similarly constituted groups ensuring school-to-school collaboration within a corporate model of self-governance established by England's government as part of its systemic reforms (DfE, 2010). In these reforms, 'more control and responsibility passes to the local level in a spirit of mutual aid between school leaders and their colleagues, who are morally committed to imaginative and sustainable ways of achieving more ambitious and better outcomes' (Hargreaves, 2010: 23). In MATs, Executive Principals are appointed to have oversight of several schools, each of which has its own principal.

Five years prior to the principal's appointment, external inspection by Ofsted (the independent 'Office of Standards in Education' which classifies the performance of schools in England) had judged the school to be 'Outstanding'. However, an audit of students' academic progress by the Executive Principal of the 
MAT had revealed that, although the students achieved raw academic results at the end of their time in school, with a 'good level of development' (GLD) in reading, writing and mathematics as defined by the English Government's Department for Education (DfE, 2010), the data on student progress and attainment on a yearly basis showed clearly that they were under-performing relative to their entry-level abilities. ${ }^{1}$ This negative, 'value-added' improvement trajectory and relatively poor pupil progress during the years since the inspection had for many staff, governors and parents, however, gone unnoticed and un-noted; and parents, for example, still believed that the school was 'at the top of its game' compared to other schools in the area.

\section{The Findings}

\section{A legacy of complacency, and difference}

Interviews with staff, parents and governors revealed continuing inconsistencies between teaching staff in expectations, practices, and ambitions. These were evidenced by: i) Functional disruption: the legacy of discontinuities and ineffectiveness of previous leadership and management; ii) Primacy of personal relationships over professional care among long serving staff: iii) A culture of comfort, complacency and lack of ambition for student progress and attainment.

\section{i) Functional Disruption: the legacy of leadership instability}

For many staff, governors and office staff, the discontinuities and ineffectiveness of a succession of recent principals had negative consequences. There had been a lack of strong, sustained leadership over a six-year period. A long-standing principal had retired. He had been succeeded by a principal who had suffered constant ill health during her two-year tenure, resulting in a lack of presence and collective loss of direction. Recruitment of a suitable successor had proved problematic, and an existing senior member of staff with 18 years of service had been appointed as 'acting' principal. U nder that more recent leadership, there had been 'no agendas or minutes of management team meetings,' and, 'Some people's ideas have been listened to more than other people's ideas.' (TA, 6 years in school).

She very much gave the appearance of being 'the principal', in a totally different way to the way that.... [previous principal]... did. He understood the staff, trusted the staff and I think that staff worked for him, whereas, for various reasons, that didn't happen with $X$. (Class teacher, 9 years in school).

At the time of the new principal's appointment, there was, 'no sense of collective purpose and direction.....management seemed to be in a state of disrepair.' (Governor, 14 years in school).

ii) Primacy of personal relationships over professional care among long serving staff 
Long-serving teachers placed more importance on harmonious personal relationships than in, 'serious conversations about improving teaching and learning. (Class teacher, 15 years teaching, 1 year in this school). They were said to have established a 'powerful friendship group that extends beyond the school gates' ( $T 2$, 20 years' experience, 2 years in this school).

They've got such a standing in the community as well. I think that they know everybody and everybody knows them. They have a key to the school. They come in the weekends, and it's 'their' school and anybody says anything against them it's the end of the world. (DH)

Their colleagues noted a 'lack of dynamic' among these teachers:

There is a lack of dynamic teaching. You've got a few teachers that have been here for a long time, stuck in their old ways and I think there's a need to have a bit more emphasis in making a bit more exciting, a bit more dynamic. (Phase leader, 8 years, 1 in this school)

iii) A culture of comfort, complacency and lack of ambition for student progress and attainment

Some people are at the end of their career and they are just coasting now towards retirement ...... Sometimes there is too much emphasis on the nurturing side, which is important... but not necessarily encouraging children to exceed their expectations of themselves. (T8)

The lethargy of the most experienced teachers, who taught Key Stage 2 students, was also expressed through their unwillingness to give more attention to raising standards of progress and attainment further, in contrast to the enthusiasm expressed by those teaching Key Stage 1 students.

The principal described the dominant vision for the school held by the senior, longserving staff as 'a place where children will be safe and happy':

We get good results, so 'Why change?'. Some people within the building still seem to be holding quite firmly to the perception that we get good results, so 'We know what's best' $(P)$.

They were perceived by the school Business manager to have a view that, since the school had been judged to be 'Outstanding' by Ofsted in 2008 and again in 2013, 'nobody can touch us'. As one class teacher observed, 'Although most teachers are adding value, some are definitely not'

I think that maybe many people here don't really know what outstanding teaching is, and I think that they need to see other people in action and realise how good 
some people are. (Phase leader, 8 years, 1 in this school)

A recently appointed teacher summarized the negative consequences of the complacency of some long-standing colleagues in challenging pupils to learn:

'....., there are things that are not going on here that should be going on, all those things that I was doing in my previous school just didn't happen here. It was the same topics, the same things all the time.... There was a lot of doing the same thing again and again, never adapting it for the class, never extending it and improving it'. (Class teacher, 3 years in school)

The discontinuities and hiatus in leadership, the positive external judgments of school results, supportive parental feedback, a culture of placing personal relationships above professional growth needs and responsibilities, and a tradition of exercising individual professional autonomy among experienced, long-serving staff, had affected the learning and achievement ambitions for their pupils.

A teacher with extensive teaching experience in other schools observed:

Things like working with lesson plans that were written in 2001; they don't even have this on computers, they have it in written folders. In my old school, we were further on in terms of management structure and planning when I left 5 years ago than we are here. (Class teacher 20 years' experience, 2 in this school)

\section{Pedagogical leadership strategies: tensions between collegial and individual professional autonomy in practice}

The principal initiated and led pedagogical change in a number of areas during his first two years, with mixed success, for example, responding to the Government's new 'assessment by levels' policy; introducing the consistent teaching of phonics; establishing a system of regular classroom observations, with an emphasis on students' progress; restructuring the leadership team; re-organizing the work of the Teaching Assistants, so that they were better able to support students with special educational needs.

In the first year, the principal focused on restructuring the leadership team, and setting new directions for working practices in classrooms, students' learning needs assessment, monitoring and data-informed teaching practices, and the introduction of school-wide behaviour management and Special Educational Needs (SEN) policies. In doing so, he promoted collegial professional autonomy, through meetings and joint decision-making based upon classroom observations and student work scrutiny, as his primary means of influencing existing mindsets and practices, building social capital through teacher collaborations and collective decision-making in which he was an active participant:

There are some things (phonics) where we've been able to change things quite quickly and almost despite what people want, and some things where the change has been 
more considered and democratic - for example, assessment for learning and marking policy. I had different approaches according to the priority, according to the pace needed in the change. $(P)$

Although the arrival of the new principal had, for some staff, brought the promise of renewed energy for change, increased academic rigour in teaching and learning, student progress and attainment, and productive partnerships, others, especially those who taught Key Stage 2 students, were less accepting. Interviews revealed a clear division between staff in terms of their willingness and confidence to respond to demands for change, particularly with regard to new accountabilities.

There still a lot of resistance and a lot of resentment. They don't see the positive effect that [the principal] has had on the school. It's almost like they're blinkered. It's a struggle. Their influence over the school is so strong that it's almost as if... there's nothing we can do.... And they've got such a standing in the community as well. I think that they know everybody and everybody knows them and they have a key to the school. They come in the weekends and it's 'their' school and anybody says anything against them it's the end of the world. (DH)

\section{A divided staff}

Although no specific questions were asked about teachers' sense of wellbeing during the period, the interviews with staff highlighted the teacher wellbeing challenges faced by the principal as he sought to engage teachers in pedagogical and belief change processes which challenged long-held notions of individual professional autonomy of a number of the more experienced teachers:

I think that there are two groups in the school. There's a group that want to see the school moving forward, changing, getting better, and I think that there's a group that has been here for a long time and that likes the way things have always been...... the challenge is unite everyone and get everybody in the same direction.... (T7)

Interview data across the three years of the research revealed two broad, stable groupings of staff opinion: i) those who supported pedagogical change through collegial decisionmaking; and ii) those who were committed to individual professional autonomy, on the basis of claims that collegial professional autonomy would lead to limiting their individual freedom to promote students' broader educational opportunities.

\section{Group 1: The Supporters}

The new deputy principal, appointed from within the school, spoke of the positive, whole school effects of the collegial professional autonomy advocated by the principal.

For the staff generally, we know where children are, we know where they need to go. I see massive change, personally. Ifeel a much more positive atmosphere around 
with the children around school. I see a vibrant school. The children are engaged, they seem happy. ...... I think a lot of the issues around SEN (Special Educational Needs) particularly were brushed under the carpet before. Children were sat in corridors doing work. Whereas now we insist that they are included in the classroom. $(\mathrm{DH})$

She praised the principal's patience in 'letting people come up with ideas themselves,' and his clear focus upon students' wellbeing as well as academic attainment:

He's very good at allowing people the opportunity to input into changes that happen. People come up with the ideas themselves but he guides them. He gives lots of opportunities for improving ourselves. It feels like we've got lots of chances for professional development. (DH)

She supported his insistence on collegially agreed changes in student assessment systems in the classroom:

Pupil progress meetings which weren't happening much before the new principal came in, things like intervention groups and having more of a hold on the SEN children and just knowing our children better and having to talk about our children more and being held to account at the end of the year when you have your appraisal. .....And regular observations, which people don't like but it's helped...we know where we're going. $(\mathrm{DH})$

However, after three years, some of those who had initially supported change had begun to doubt the principal's ability to achieve this across the school. Brenda was a Year 1 and 2 Phase Leader and had been at the school for 3+ years, having taught elsewhere previously. She supported the changes that her principal wanted, but was critical of his early collegial stance in which he had been less directive than she would have preferred. The result of this had been that he had failed to 'win over' those who doubted the need for pedagogical change. Evidence of this was, she stated, to be found in inconsistencies in the implementation of the whole school behaviour policy, lack of curriculum reform and 'robust' discussion among members of the Senior Leadership Team (SLT).

I think there comes a point where you have to say 'I'm telling you how to do this, I'm offering you reasons why you've got to do it. If you're not gonna do that, these are gonna be the consequences'. He sits on the fence too much and doesn't give you enough.. .....I'm now in a place with a team of people who've been there for a long time and they are very, very hardworking people, but they like to do things the way they've always done them. They can get very uncomfortable if you try and change even some things which you think are obvious that you've got to change. I think we very clearly need to know what the development priorities are, but we haven't had robust enough discussions as an SLT (Senior Leadership Team) about how we're going to get to them and the timescales for getting to them and the support that we're going to put in for people.(T1) 
Teachers in this group had refused to accept the otherwise collective agreements about how student progress might be enhanced. Lesley was a Key Stage2 teacher (10-11 year olds), had taught at the school for 15 years, and remained unconvinced of the need to change. She pointed particularly to the demands of the increased bureaucracy in implementing the marking scheme that the principal had introduced, the introduction of detailed classroom tracking of student progress, and changes in support structures for students with significant learning difficulties for the purpose of differentiation in teaching, all of which had been agreed by Key Stage 1 teachers.

I think that there is still a significant amount of work that we are asked to do which we don't believe in, or at least that we feel is unnecessary ... for instance I think there are a lot of people who are adhering to the marking policy - I'm one of them - but aren't quite sure whether it's worth the amount of effort that were putting into it, in terms of whether or not the children read it, or if they have opportunity to read it. We're meant to give them opportunity to read it, but in a crowded timetable I just don't think that's practical a lot of the time. The amount of time we spend marking has increased phenomenally and I'm not certain that there has been a proportional improvement in the work that they've produced.

Another teacher, with 19 years of service in the school, listed the changes that had, by implication, adversely affected her world of teaching: i) 'Now everything has become much more boxed. Everything is answerable, very results driven, very much on attainment'; ii) 'The Christian element was an underlying part of day to day life, and over the last 3 or 4 years things have changed drastically.' and iii) 'Sometimes you are fighting a bit for the wider development of the whole child.'

An experienced teaching assistant also expressed a deep sense of change induced fatigue:

'There was a certain point in my career, it was probably about two years ago, where I just said I'm tired of all the change, I'm tired of all the distress and the negativity that comes with change... so I still give my 100\% to the children, but I keep out of any issues within the school in terms of politics and staffing problems... I don 't want to give my life to that.' (TA3)

\section{Students' academic progress and attainment: a mixed picture}

The principal's reform-related, 'improvement' agenda through his promotion of collegial professional autonomy met with only partial success. Those who taught Key Stage 1 students (5-7 year olds) collectively re-oriented their planning, teaching and assessment practices so as to take account of the government's standards agenda. However, they could not be said to be 'compliant', nor to have experienced diminishing 
autonomy or de-professionalisation, since they had not abandoned their broader educational beliefs, values, and practices. In contrast, a group of long-standing, experienced, highly efficacious and committed teachers, many of whom regarded themselves and were regarded by parents as doing a good job, continued to assert their right to exercise what they claimed to be their professional autonomy in deciding individually how they planned, taught, monitored and assessed their Key Stage 2 students (7-11 year olds), despite evidence that they were under-performing.

Over the principal's first three years, it became apparent that in Key Stage 1, (5-7 year olds) students' progress and performance in reading, writing and mathematics, according to national tests, had improved. In the three years 2013-2016, results in Phonics in Key Stage 1 rose from $45.5 \%$ in 2014, to $80 \%$ in 2015, and $93 \%$ in 2016. However, this improvement was not matched by students at Key Stage 2 (7-11year olds). Here, progress over the same period in Reading was below the national average (61\% versus $66 \%$ ); and progress in Mathematics was well below the national average (56\% versus $70 \%$ ). When these results were combined, the 'Good Level of Development' of 1011year old students in River Edge was rated at $46 \%$ as against a national average of $53 \%$. Strikingly, by 2016, the Key Stage 2 students at this school, drawn from a relatively socio-economically advantaged community, were judged to be performing on a par with those attending schools in the area which had a greater proportion of economically disadvantaged students.

\section{Discussion}

Evidence from the research i) challenges claims that reform necessarily results in school cultures of compliancy, de-professionalisation, and the technicisation of teaching; ii) raises issues concerning the pedagogical approaches of principals in leading and managing teachers' work in a devolved, 'self-governing' school system; and iii) questions teachers' rights to individual classroom autonomy where this is associated with their students' academic under performance.

Policy developments internationally are claimed to be directly related to widespread reports of poor recruitment, burnout, early attrition, and low morale among many teachers (Breslin, 2002; Ingersoll, Merrill, \& Henry, 2016; Lindqvist, P., Nordänger, U. K., \& Carlsson, R; 2014; Liu, S., \& Onwuegbuzie, A. J; 2012; Smithers \& Robinson, 2003); and researchers have highlighted the pedagogical challenges, professional tensions, and ethical dilemmas that education policies and reforms have produced for teachers as constituting a potential threat to their ability to strive to offer a 'good' education and engage in 'meaningful' professional conduct (Fuhrman, 1999; Mitchell, Crowson \& Shipps, 2011). They have produced, it is claimed:

a situation where measurement has become an end in itself rather than a means to achieve a good education in the fullest and broadest sense of the term' (Biesta, 2015:83).

The findings from this research challenge this apparent cause and effect relationship 
between policy demands and teacher compliance. Long ago, Elmore (2003) concluded that a common misconception of policymakers is "the belief that policies determine how individuals and organizations think and act —what problems they regard as important, how they organize themselves to work on those problems, what results they regard as evidence of their success" (Elmore, 2003: 195); and more recent research in English secondary schools found that schools 'enact' rather than 'implement' externally initiated reforms, interpreting and contextualising, rather than strictly implementing ( Ball, Maguire and Braun, 2012). That research, albeit conducted in secondary schools, found also that there was a, 'dearth of values-talk':

Social values and principles of social justice are less than obvious components of the policy process.... It is often the case that ethical-democratic concerns come into play only weakly over and against and within the interpretation and enactment of policy. (Ball et al., 2012, p. 10)

However, it was clear from the interviews at River Edge over three years that satisfying external policy demands was never the primary goal for either the principal or the staff, and that social values and principles of social justice were an ongoing part of the improvement agenda. It was teachers' moral values, a commitment to make a positive difference to the learning progress of the students, that were the driving force.

Moral purposes are at the centre of all teachers' understanding and application of their responsibilities to act in the broader rather than narrower interests of the student. They define their motivations, purposes, actions, and professional identities (Author et al, 2007; Hansen, 1998; Nias, 1999). The principal's twin emphasis upon developing and using measures which enabled them to differentiate more finely between the learning needs and progress of individual students, and equity of care in re-structuring the education of 'special educational need' students, supported their moral purposes, and was welcomed by the majority. Those teachers who enhanced their pedagogical practices and fine-tuned their systems of monitoring student progress and achievement through collegial professional autonomy did not state that their individual professional autonomy was under threat. They had not abandoned their broader educational purposes and practices, but incorporated the new practices into these. They were pleased that the progress and attainment of their students in literacy and numeracy improved over the three-year period of the research. However, those who refused to countenance a loss to their individual professional autonomy continued to prioritise their broader purposes over increasing the academic progress and performance of their students on the grounds of their long-held notion of strong moral purpose, and their sole authority to judge what was right for the betterment of their students. They believed that the education that they were providing benefited their students' broad development needs. They did not accept that planning and teaching in new ways would add value to their students' opportunities to improve their academic progress and achievement, despite clear evidence that their students were under-performing.

There may be several reasons that these teachers would not engage in new pedagogical 
classroom practices. For example, they may have been unable or unwilling to summon the additional energy needed, or have lacked the commitment to improving their students' progress and attainment. There was no evidence, however, of either of these among these teachers. Rather, they used the claim to individual professional autonomy as a way of excusing their resistance, despite the decline over three years in their students' progress and attainment.

It may be argued, then, on the basis of these data, that these teachers were disadvantaging their students, and that one example of this was a decline, rather than improvement, in students' academic progress and attainment.

The meanings and practices of teacher professionalism continue to be a topic of considerable debate, especially among academics in many countries who are variously concerned that changes in national policy demands, particularly external inspection and regulated student assessment related to the achievement of success in particular areas of the curriculum, threaten its key components: qualification following a period of extended training, teacher autonomy and discretionary decision-making. Although 'autonomy' is generally recognised as being central to the ability of teachers to function as professionals, different kinds of autonomy and the use of these in practice have rarely been examined in contexts of changes in school governance, contexts, conditions, and expectations.

\section{ii) Pedagogical leadership approaches: the (new?) responsibility of principals}

'... the most prevalent universal intervention among OECD countries has been to increase the accountability of schools and schooling systems through the assessment of student performance' (Willms, 2006: 13).

As many national education systems continue to promote devolved governance, so there has been an increase in principals' pedagogical leadership responsibilities. Under the 'self-improving' system of school governance in England, for example, principals are directly responsible and accountable to government for raising the academic standards of students.

This has caused the balance in the school system in England, as in many countries, to shift towards the increased use of authority by the principal and away from trust in individual teachers' ability to make decisions about student learning, progress and attainment in their classrooms. The extent to which teachers are able to exercise individual professionalism now does not depend only on the relative strength of their own knowledge, skills and moral purposes but now also on how the principal uses his/her pedagogical authority in establishing the collective values expressed in the cultures of the schools in which they work. Thus, how principals interpret and manage this authority in externally initiated neo-liberal reform contexts may now determine how their teachers experience professional autonomy. 
Schleicher $(2018 ; 96)$ argues that, 'rarely do teachers own their professional standards to the extent other professionals do, and rarely do they work with the level of autonomy and in the collaborative work culture that people in other knowledge-based professions take for granted.' This research found that under the leadership of a newly appointed principal, whilst teachers' individual professional autonomy was reduced, their collective professional autonomy was increased. The principal used his pedagogical authority to promote improvements in the academic progress and attainment of all students, and this was paralleled by the development of a social justice inspired inclusive agenda. He did so through leading and modelling collegial professionalism.

This was embraced by the majority of staff, who reaped the associated rewards of seeing increased student progress and attainment, whilst sustaining their broader educational purposes and practices. However, a minority of experienced, influential staff insisted on their rights in continuing to engage in what they claimed to be their individual professional autonomy, despite seeing a decline in the 'value-added' progress and attainment of their students. These teachers were unwilling to acknowledge that their teaching was simply not good enough in terms of value-added progress and attainment; and that student progress and attainment were below the levels which could reasonably be expected of them. Whilst it is not possible to establish a direct cause and effect relationship between teaching and student performance, without taking account of other variables (Fenstermacher and Richardson, 2005), it is reasonable to infer an association when different cohorts of students of a teacher under-perform academically in terms of their progress and measured attainment over that teacher's three consecutive years of teaching.

It may be argued that the principal's pedagogical approach of collegial professional autonomy met with only partial success, and that other alternative approaches might have been used with those who refused to abandon what they claimed to be their right to exercise individual professional autonomy. His inability to harmonize internal social relationships point to deeper issues concerning the meanings of 'professionalism' and 'autonomy', which privilege a more functional focus on evidence-informed teaching through which teachers are able to work more effectively towards realising the academic potential of their students.

Under devolved school systems, how principals' lead and manage teachers' sense of professionalism is important, because it defines how their teachers experience professional autonomy. This is especially the case where national reform agendas give more responsibility and accountability for the leadership, management and students' academic outcomes to school principals. This research adds to the evidence of a range of research internationally that reforms do not necessarily result in a loss of autonomy or the de-professionalisation of teachers, but that autonomy itself needs to be understood in different ways (Day et al, 2016, 2017; Gu et al, 2018). These and other studies have acknowledged the complexities and challenges, but also the benefits of the new, reforminduced teacher professionalism, to the ways in which teachers in schools exercise autonomy in practice, through the mediating effects of school leaders.

\section{iii) \\ Teachers' entitlements to individual professional autonomy}


Forrester's (2000) case study of managerialism in a primary school provides an example of the dynamic interplay between organizational /social structures and individual agency (Giddens, 1979) as interdependent. She suggested that, 'teachers' notions of professionalism as understood by them in the past, have been displaced, and their professional autonomy, judgment and expertise denied by the shift in the control of education towards central government' (p. 147). However, whilst the shift may be constraining, it may also be enabling (Giddens, 1976). The evidence from staff at River Edge School shows that the exercise of individual professional autonomy over collegial professional autonomy hindered rather than progressed student learning but that 'general professional autonomy' was thriving. Teachers of students in the Key Stage 1 phase collectively enacted a managerially driven agenda of raising standards of student performance because this corresponded to the moral purposes and professional values and aspirations, without displacing their notions of professionalism and, within this, autonomy. They did not see themselves as being compliant, and so maintained their sense of general professional autonomy. On the other hand, teachers of Key Stage 2 students asserted their right to exercise individual professional autonomy, placing themselves in conflict with colleagues who embraced the principal promoted agenda of collegial professional autonomy.

Claims to rights to exercise individual professional autonomy were used by these teachers as a reason not to change. They associated collegial professional autonomy with unnecessary increases in workload, and a narrowing of their broader teaching and learning agendas, a leadership strategy to achieve compliance with the implementation of government policies (Forrester, 2000). These teachers might be said to be using the language of individual professional autonomy as a means of either opposing the principal's exercise of pedagogical leadership in order to improve students' academic progress and attainment, justifying their role in their students' relative under-performance, or both. It may also be that they were at a phase in their careers when they did not possess or were unwilling to raise the energy necessary to engage in change itself, though there was no evidence of this.

The research does not challenge claims that autonomy has been reduced for teachers, in terms of their individual freedom and capacity to choose what and how to teach and assess students' learning needs. Rather, it questions whether this reduction has made any difference to their general and collegial sense of autonomy and their moral and ethical purposes and practices, when an essential part of moral purpose is an ongoing commitment to contribute to the progress and attainment of their students, and their sense of professional autonomy.

\section{Conclusions}

The research reported in this paper adds to the evidence internationally that reforms do not necessarily result in the de-professionalisation of teachers, but that autonomy itself needs to be understood in different ways. It has provided insights into leadership and teaching in schools in reform contexts that exert external pressures which promote an 
emphasis upon students' measurable progress and attainments; and illustrates ways in which teachers' general professional autonomy in practice may be supported through collegial professional autonomy. It has also highlighted the challenges to principals when individual and collegial professional autonomy are enacted within the same school, the negative effects of the former and positive effects of the latter upon both staff relationships and student progress and achievement.

These findings are embedded in tensions between 'freedom to choose and responsibility for choice' (Brint, 2006: 108). Over the three-year research period these tensions remained unresolved at River Edge, as a group of experienced teachers continued to assert their authority for their individual professional autonomy, challenging the collegial professional autonomy of their colleagues. Whilst their position may be regarded as untenable in relation to teachers' moral purposes where these include seeking to include meeting the needs of students in terms of academic progress and attainment., it does not necessarily illustrate obduracy:

'...Submitting to the control of an occupational community is difficult and unsatisfying for many people at times; it is a restriction of freedom as much as a prevention for freedom. It requires the willingness to accept autonomy of professional teachers... This takes courage, and it requires identification with occupational elites, rather than managers or clients (Brint, 2006 p. 120).

For the majority of teachers at River Edge, even in an era of unprecedented reform, being and behaving as a professional continued to be associated with having a strong technical culture (knowledge base); service ethic (commitment to serving clients' needs); professional commitment (strong individual and collective identities); and professional autonomy (control over classroom practice), though this latter was now framed collegially by the principal. Although policy trends have changed teachers' orientations to work (Leicht and Fennell, 2001), general claims that, as a result, teachers have become 'technicians' whose professionalism has been compromised would appear to be unfounded in practice in this school. An important, as yet relatively unexamined issue, however, is whether some teachers should be able to avoid participation in whole school 'performativity' orientations through collegial professional autonomy, by continuing to exercise individual professional autonomy, if the effect of such non-participation is to deny the students the opportunity to develop their academic potential.

Notes

1. Judgments of teacher performance in schools in England have come to be closely associated with their ability to 'add value' over each year to the level at which their students entered their classrooms. These are then aggregated at school level and compared with results from schools that serve similar socio-economic communities. In this sense, schools can be differentiated as performing well or under-performing, when performance is measured against their students' own previous performance and the socio-economic histories of their students. This is known as 'context value added' (CVA). Although CVA 
measures have been criticized for, 'the extent to which they successfully control for timeinvariant factors' (Gorard et al; 2013, in Morris et al; 2018:726), they are widely used within schools in England as a reliable means of measuring student progress that is, 'independent of the selection of pupils, background characteristics and innate ability' (Morris et al; 2018: 726; Chetty et al; 2014). This is regarded as a fairer way of assessing their progress, and their teachers' contribution to this, than raw attainment measures. Because these measures allow teachers to judge and be judged on their ability to raise levels of student performance on a yearly basis, it may be argued that they could be used to ensure that teachers and their teaching are compliant with the performativity agenda of government, and that this challenges cherished notions of teachers' individual professional autonomy.

\section{References}

Apple.M.W. (2008) Can schooling contribute to a more just society? Education, Citizenship and Social Justice 3(3), 239-261.

Ball, S. J. (2012). Global Education Inc: New Policy Networks and the Neo-liberal Imaginary. London: Routledge.

Ball, S. J., Maguire, M., \& Braun, A. (2012). How schools do policy: Policy enactments in secondary schools. Oxon, London: Routledge.

Bransford, J; Darling-Hammond, L; and Lepage, P. (2005) Introduction. In, L.DarlingHammond \&J. Bransford (Eds), Preparing teachers for a changing world: What teachers shouls learn and be able to do (1-39). San Francisco: Jossey-Bass.

Breslin, T. (2002). Chasing the wrong dream: The quest for teacher professionalism in the age of the citizenship school. In M. Johnson \& J. Hallgarten (Eds.), From victims of change to agents of change: The future of the teaching profession. London, England: IPPR.

Brint, S., 2006. Saving the "soul of professionalism": Freidson's institutional ethics and the defense of professional autonomy. Knowledge, work and society, 4(2), pp.101-129.

Biesta, G. (2015). What is Education For? On Good Education, Teacher Judgement, and Educational Professionalism European Journal of Education, Vol. 50, No. 1, 2015.

Charmaz, K. (2014) Constructing Grounded Theory: $2^{\text {nd }}$ Edition. Los Angeles, CA. Sage Publications.

Chetty, R; Friedman, J. N; and Rockoff, J. E. (2014). Measuring the impacts of teachers 1: Evaluating bias in teacher value-added estimates, The American Economic Review, 104, 2593-2632. https://doi.org/10.1257/aer.104.9.2633

*Day, C. \& Gu, Q. (2007) Variations in the conditions for teachers' professional learning and development: Sustaining commitment and effectiveness over a career. 
Oxford Review of Education, 33 (4): 423-443.

Day, C; Qu, Q; Sammons, P (2016) The impact of school leadership on student outcomes: how successful leaders use transformational and instructional strategies to make a difference. Educational Administration Quarterly, 52(2): 221-258.

Day, C. (2017) Teachers' Worlds and Work: understanding complexity, building quality. London: Routledge.

Department for Education (2010) The Importance of Teaching. The Schools' White Paper, Norwich, TSO.

Elmore, R. G. (2003). The challenges of accountability: A plea for strong practice. Educational Leadership, 61(3), 6-10.

Fenstermacher, G. D; \& Richardson, V. (2005). On making determinations of quality in teaching. Teachers College Record, 107 (1), 185-2015.

Forrester, G., 2000. Professional autonomy versus managerial control: The experience of teachers in an English primary school. International Studies in Sociology of Education, 10(2), pp.133-151.

Frostenson, M. (2015). Three forms of professional autonomy: de-professionalisation of teachers in a new light. Nordic Journal of Studies in Educational Policy. 2015: 2 pp. 2029.

Fuhrman, S. H. (1999). The new accountability. Philadelphia: Consortium for Policy Research in Education.

Gorard, S; Hordosy, R, and Siddiqui, N. (2013) How unstable are 'school effects' assessed by a value-added technique? Journal of Studies of International Education, 6, 19. https://doi.org/10.5539/ies.v6n1pl

Giddens, A. (1976) New Rules of Sociological Method: a positive critique of interpretative sociologies. London: Hutchinson.

Goodlad, J. I. (1990). Places where teachers are taught. San Francisco: Jossey Bass.

Gu, Q; Day,C; Walker, A; and Leithwood K. (2018) How Successful Secondary School Principals Enact Policy. Leadership and Policy in Schools. 17(3), 327-331.

Hall, C and Noyes, A. (2009) New Regimes of Truth: The Impact of Performative School Self Evaluation Systems on Teachers' Professional Identities. Teaching and Teacher Education, 25: 850-6 .

Hargreaves, A (2003) Teaching in a knowledge society: Education in the age of insecurity. New York: Teachers College Press.

Hargreaves, A., \& O'Connor, M. (2018). Collaborative professionalism: When teaching together means learning for all. Thousand Oaks, CA: Corwin. 
Hargreaves, A. and Fullan, M. (2012). Professional Capital: Transforming Teaching in Every School. New York, NY: Teachers College Press.

Hargreaves, D. H. (2010). Creating a self-improving school system. Nottingham UK: National College for Leadership of Schools and Children's Services: 1-25

Hyslop-Margison, E. J; \& Sears, A. M. (2010) Enhancing Teacher Performance: The Role of Professional Autonomy. Interchange, Vol. 41/1, 1-15, 2010 (C) Springer 2010 DOI: $10.1007 / \mathrm{s} 10780-010-9106-3$

Leicht, K.T. \& Fennell, M. L. (2001). Professional work: a sociological approach. Malden: Blackwell.

Ingersoll, R., Merrill, L., \& Henry, M. (2016). Do accountability policies push teachers out? The Working Lives of Educators, 73(8), 44-49.

Leicht, K. T; \& Fennell, M (2001). Professional work: A Sociological Approach. Oxford: Blackwell.

Lindqvist, P., Nordänger, U. K., \& Carlsson, R. (2014). Teacher attrition the first five years-A multifaceted image. Teaching and Teacher Education, 40, 94-103.

Liu, S., \& Onwuegbuzie, A. J. (2012). Chinese teachers' work stress and their turnover intention. International Journal of Educational Research, 53, 160-170.

Lortie, D. (1975). Schoolteacher: A sociological analysis. Chicago, IL: University of Chicago Press.

Miles, M. B., \& Huberman, A. M. (1984). Qualitative data analysis: A sourcebook of new methods. In Qualitative data analysis: a sourcebook of new methods. Sage publications.

Mitchell D.E.; Crowson R.L. \& Shipps.D.(2011) Shaping the Education Policy Dialogue. Peabody Journal of Education. 86(4), 367-372.

Morris, T. T; Davies, N. M; Dorling, D; Richmond, R. C; and Davey Smith, G (2018) Testing the validity of value-added measures of educational progress with genetic data. British Educational Research Journal. Vol.44, No. 5, October 2018, pp. 725-747.

Nias, J. (1999) Teachers' Moral Purposes: stress, vulnerability, and strength. In R. Vandenberghe and A. M. Huberman (Eds) Understanding and Preventing Teacher Burnout: A Sourcebook of International Research and Practice. Cambridge. Cambridge university Press, 223-237.

Ozga, J. (2008). Social Capital, Professionalism and Diversity: Studies in Inclusive Education (with J. Allen, G. Smyth). Rotterdam: Sense Publishers.

Ozga, J. (2012). Governing knowledge: data, inspection and education policy in Europe. Globalisation, Societies and Education, 10 (4), 439-455. 
Pitt, A. (2010) On Having One's Chance: Autonomy as Education's Limit. Education Theory 60 (1), 1-18.

Sachs, J. and Mockler, N. (2012). Performance cultures of teaching: threat or opportunity?' In C. Day (Ed.), International Handbook of Teacher and School Development. London: Routledge, 33-43.

Schleicher, A. (2018) World Class: how to build a $21^{\text {st }}$ century school system, Paris, France: OECD,: 96.

Smithers, A, \& Robinson, P. (2003) Factors affecting teachers' decisions to leave the profession. Research report 430. London: Department of Education and Skills.

Troman, G. (2008) Primary teacher identity, commitment and career in performative school cultures. British Educational Journal, 34 (5): 619-633.

Wellington, J. (2000). Educational Research: Contemporary Issues and Practical Approaches. London, Continuum.

Willms, J. D. (2006) Learning divides: Ten policy questions about the performance and equity of schools and schooling systems (No. UIS/WP/06-02). Montreal, QC: UNESCO Institute for Statistics: 1-81.

Yin, R. K. (2009). Case Study Research: Design and Methods, 4th edition. Thousand Oaks, CA. Sage. 